\title{
Traduzir O estrangeiro, de Albert Camus: PENSAR A LUZ ESTRANGEIRA NA LITERATURA EM PROSA
}

\author{
Gilles Jean Abes ${ }^{1}$
}

Resumo: O objetivo deste artigo é apresentar uma leitura da novela $O$ estrangeiro, de Albert Camus, publicada pela primeira vez em 1942, pautado no conceito de "lumière étrangère" [luz estrangeira], advindo das artes plásticas. A análise do protagonista é crucial e tem como base obras de José Régio, D. H. Lawrence ou ainda cartas de Mário de Andrade. Num segundo momento, pretende-se detalhar o gesto singular que emana da tradução dessa obra e que busca assimilar conscientemente aquele elemento estrangeiro. Em seguida, será necessário ressaltar as divergências da nossa tradução para o português brasileiro, com as que estão disponíveis no mercado, para mostrar que o elemento estrangeiro pode provocar um grande desconforto para o tradutor, que tenderá a neutralizá-lo. Num terceiro momento, procura-se estabelecer uma reflexão, a partir do exercício tradutório, para ressaltar problemas específicos à tradução de textos literários em prosa. Essa reflexão passa por teóricos como Antoine Berman e Haroldo de Campos, notadamente na problematização dos conceitos de "informação semântica" e "informação estética", elaborados por Max Bense.

Palavras-chave: Camus; $O$ estrangeiro; tradução.

"À força de procurar o que Kafka quer dizer, mas não diz, tornamo-nos cegos para as palavras que ele escreve em preto no branco.”

(Marthe Robert)

1 Professor do Departamento de Língua e Literatura Estrangeiras e da Pós-Graduação em Estudos da Tradução da Universidade Federal de Santa Catarina, e-mail: <gillesufsc@ gmail.com>. 


\section{TRADUÇÃO: PRIMEIRO PARÁGRAFO DE O ESTRANGEIRO}

Hoje mamãe morreu. Ou talvez ontem, não sei. Recebi um telegrama do asilo: "Mãe falecida. Enterro amanhã. Condolências". Isso não faz sentido. Pode ter sido ontem, talvez.

Aujourd'hui, maman est morte. Ou peut-être hier, je ne sais pas. J'ai reçu un télégramme de l'asile : "Mère décédée. Enterrement demain. Sentiments distingués.” Cela ne veut rien dire. C'était peut-être hier. (CAMUS, 1990, p. 9)

\section{CONSIDERAÇÕES INICIAIS}

Ao abordar uma novela como $O$ estrangeiro, de Albert Camus, publicada pela primeira vez em 1942, sabemos que nossa leitura será influenciada por outras que, como um rumor persistente e subterrâneo, ecoam sobre aquilo que elegemos como pertinente, transpassando as soleiras do texto. Como afirma Antoine Compagnon (2011, p. 5), na impossível busca por definir o que seria um clássico, um de seus componentes seria a sua imperfeição: "A obra clássica não é perfeita. É porque não é perfeita, não é canônica, se preferirem, porque é entranhada de diferenças que tem o poder de tornar-se clássica”. ${ }^{2}$ Paradoxo, portanto, que possibilitaria, nessa imperfeição, a existência desses ecos ou diferenças e, assim, de novos leitores e leituras. O rumor como garantia provisória de sua pervivência (conceito de Benjamin) e proliferação (no sentido rizomático de Deleuze e Gattari). É óbvio que a literatura é objeto heterogêneo e proteiforme e, assim sendo, podemos nos deparar com uma obra que faça vacilarem argumentos e definições, ruindo a qualquer momento, como castelo de palavras, sob o efeito mínimo de um leve deslocamento. A literatura contra a literatura.

Assim, tomo apenas um traço possível dessa definição de Compagnon para pensar a novela camusiana: o componente imperfeito do clássico entranhado de diferenças. Com efeito, $O$ estrangeiro é exemplar. É o clássico por excelência, imbuído de imperfeição, posto que entranhado de lacunas: a ausência de análise, explicações e pensamentos por parte do protagonista/narrador, o famoso Meursault, que possam ilustrar ou justificar suas escolhas e atitudes. O componente principal dessa novela,

2 “L'œuvre classique n'est pas parfaite. C'est parce qu'elle n'est pas parfaite, pas canonique, si vous voulez, c'est parce qu'elle est creusée de différences qu'elle a le pouvoir de devenir classique." Todas as traduções do francês, quando não especificadas, são minhas. 
seu signo, é a elipse. Diante dessa falta, o incômodo do leitor é patente, experiência similar à leitura de outra novela, A metamorfose, de Kafka. Não é fortuito que Camus tenha dedicado um ensaio a respeito do autor de $O$ processo ("L'espoir et l'absurde dans l'oeuvre de Franz Kafka" [A esperança e o absurdo na obra de Franz Kafka]). Nessas narrativas, pouco se diz, já que o narrador é insciente. Mas nesse ínfimo dizer tecem-se inúmeras relações que, no caso de $O$ estrangeiro, se observadas em contraste - as ações do protagonista e as contradições dos outros personagens - descortinam uma reflexão profunda sobre a condição humana e a experiência do absurdo. Cabe justamente ao leitor preencher as lacunas e procurar seguir essa complexa trama, tarefa que potencializa o texto, mas que, simultaneamente, produz desconforto e incompreensão.

Traduzir tal texto apresenta assim uma dificuldade latente que vai além das competências linguísticas e literárias, ou da experiência e cultura geral do tradutor. Também não é mera ponte entre duas culturas. O desafio maior talvez seja o de lidar com esse desconforto provocado pela potência do texto de Camus, a tarefa não apenas de hospedar o elemento estrangeiro do texto, em sua narrativa ou nas atitudes do personagem, mas também de reproduzir o caráter elíptico da novela, no agenciamento lacunar das palavras. Sua potência está marcada por uma ausência. Seu poder é elíptico. E o desconforto, que decorre dessa falta, constitui um elemento perturbador para o tradutor, que precisa se dar o tempo para acolhê-lo. Não deve apagá-lo, por mais que uma súbita pulsão deseje conduzir sua mão (gesto inconsciente), para apaziguar o desconforto que se agita em seu interior ao acompanhar os supostos comportamentos absurdos de Meursault e a linguagem estrangeira da narrativa. Se há, como afirma Antoine Berman (1995, pp. 74-75), uma pulsão de traduzir, pulsão que pode inclusive advir da leitura de uma tradução, que produz um impulso para uma retradução, também haveria uma pulsão que contamina o gesto tradutório negativamente. A consequência seria a busca por restabelecer inconscientemente a ordem e eliminar aquele elemento intruso que lhe causa um desconforto palpável, físico até, com uma linguagem normatizada, conhecida, apaziguadora, em outras palavras, uma linguagem familiar. Para aplacar esse tremor interior, é preciso neutralizar essa linguagem estrangeira.

O propósito deste artigo é, em primeiro lugar, o de apresentar uma leitura possível da novela camusiana, desse elemento estrangeiro do texto, a partir de outras obras literárias, notadamente, o conto do autor 
português, José Régio (1973), “Os alicerces da realidade”, publicado na coletânea Há mais mundos, em 1962. A correspondência de Mário de Andrade e Carlos Drummond de Andrade (2002) e o ensaio, Caos em poesia, de D. H. Lawrence (2016), também formam fontes valiosas para auxiliar a interpretação do gesto absurdo do protagonista. Num segundo momento, pretende-se detalhar a postura pensante que emana da tradução dessa novela. Há mais mundos possíveis a partir de sua leitura e o gesto tradutório convive intimamente aqui com a assimilação consciente do estrangeiro. Para tanto, será necessário ressaltar as divergências da nossa tradução para o português brasileiro, com as que estão disponíveis no mercado, sobretudo a publicada pela Record, que já alcançou 42 edições. Com essa análise crítica das traduções de $O$ estrangeiro, busca-se reafirmar a hipótese da influência desse desconforto sobre o gesto do tradutor. Num terceiro momento, procurar-se-á estabelecer uma reflexão teórica, a partir do exercício tradutório, que poderia, assim espero, ressaltar problemas específicos à tradução de textos literários em prosa. A reflexão tem como ponto de partida a novela de Camus, mas também passa por teóricos como Antoine Berman e Haroldo de Campos, notadamente na problematização dos conceitos de "informação semântica" e "informação estética", elaborados por Max Bense. Finalmente, cabe ressaltar que a tradução de O estrangeiro, que acompanha este artigo, é apenas do primeiro parágrafo, que se torna aqui central para minha reflexão em consonância com a obra como um todo.

\section{MEURSAULT: O HOMEM ABSURDO}

Uma das armadilhas na qual pode cair um leitor de $O$ estrangeiro é ter seu olhar arrastado por Meursault, protagonista/narrador da novela, e desviado dos outros personagens. Outro problema está na simplificação, decorrente em parte da atenção voltada para o personagem principal, dos atos de Meursault julgados simploriamente como absurdos, inadequados àquela sociedade, sentenciados como estranhos e insensíveis.

Minha proposta de leitura consiste em uma mudança de foco. Decentralizar o olhar. Enxergar o texto e os personagens como através de um caleidoscópio. Observar as palavras em preto no branco, para entrever as contradições das atitudes e falas dos personagens.

Devo iniciar minha reflexão com o nome do protagonista. Meursault é, propositalmente ou não, em francês, exata homofonia da frase formada pelo verbo "morrer", na segunda pessoa do imperativo, e mais a palavra 
"sot": Meur-sault = "Meurs sot!", ou seja, traduzindo para o português brasileiro, "Morre tolo!" ou "Morre imbecil!". A palavra "sot", muito frequente nas peças do Molière, é sinônima de "imbecil" ou "tolo", mas foi caindo em desuso, substituída por "idiot" ou "imbécile”. No dicionário, a primeira acepção é: "desprovido de inteligência ou de bom senso", o que nos leva aos sentidos de tolice ou imbecilidade. Mas, muito mais pertinente é a situação da palavra na expressão "se trouver (tout) sot", que significa "manifestar perturbação, embaraço, inabilidade" diante de uma situação. Podemos agora entender o nome do personagem como uma condenação: Morre desajustado!, Morre inábil!" ou ainda "Morre desloucado!", lembrando aqui do trocadilho de Günther Anders (2007).

Outra acepção curiosa é o sentido da palavra na Baixa Idade Média, como "bobo da corte" que atua em uma "sotie". A "sotie" era uma farsa satírica na moda nos séculos XIV e XV e que consistia numa crítica burlesca da sociedade e dos costumes da época. André Gide (COTE-OSTIGUY, 2013, p. 73) chega a qualificar algumas de suas narrativas de "sotie", entendendo-as como obras críticas ou irônicas. Os atores eram assim chamados de "sots" ou "fous", vocábulos cuja polissemia diz muito da leitura que se pode fazer de Meursault: "fou" significando, além de "bobo da corte", "louco". Pouca importa se foi essa ou não a intenção de Camus, de jogar com essa homofonia. Italo Calvino considera que os nomes de personagens são muito importantes e sugere até mesmo a ideia de uma história da literatura ou do gosto literário considerando os nomes dos personagens. Observa também duas tendências principais para a constituição deles, geralmente formados

\footnotetext{
Por nomes que pesem o menos possível, que não constituam nenhum diafragma entre os personagens e o leitor, nomes de batismo comuns e intercambiáveis, quase números para distinguir um personagem do outro; ou por nomes que, mesmo não significando nada diretamente, tenham um intrínseco poder evocativo, sejam uma espécie de definição fonética dos respectivos personagens e, uma vez colados a eles, não se possam mais destacar, tornando-se ambos uma só coisa. (CALVINO, 2015, p. 12)
}

Eis o sobrenome do personagem principal, que aliás não possui prenome - lógica invertida dos personagens de Kafka (Joseph K. x Meursault). Temos aqui os dois exemplos de Calvino, o nome comum, Joseph, e o sobrenome que não significa de imediato algo e que soa bastante verossímil, mas que pode, como vimos, emanar um forte poder evocativo: "Meurs sot!". Não há como não lembrar de outra homofonia, a 
do nome da protagonista de Madame Bovary (1857), de Gustave Flaubert, Emma Bovary: "Emma/ Aima/ Amou", Bovary derivando da palavra "bovino".

Com essa perspectiva, o homem absurdo passa a representar o "desajustado" e "inábil" diante de uma sociedade que aparenta uma peça de Beckett ou Ionesco. Mas, simultaneamente, e na tensão de um paradoxo, o homem absurdo se torna, aos poucos, um observador dessa mesma sociedade, deslocado e curioso de suas contradições. O melhor exemplo dessa atitude é a forma como parece analisar a atuação do promotor, permanecendo o narrador como que estrangeiro a seu próprio julgamento. De maneira simultânea e contraditória, Meursault se assemelha ao bobo da corte, que atua numa farsa satirizando aquela sociedade e seus costumes, convenções naturalizadas como a proposta de casamento de Marie: "[Marie] observou então que o casamento é coisa séria. Respondi: 'Não”' (CAMUS, 2017, pp. 48-49). O personagem recusa jogar o jogo, não tanto porque não compreende as regras, mas justamente porque, com uma lucidez sem concessão, sente que as regras não são naturais e camuflam, como para D. H. Lawrence, o caos do mundo. Meursault sente os pormenores da realidade, um pouco como a poesia que faz um novo esforço de atenção e "descobre" um novo mundo dentro do mundo conhecido. O protagonista de $O$ estrangeiro é o oposto do homem-lugar-comum do ensaio de Lawrence (2016, [s.p.]), Caos em poesia, de 1928. O homem absurdo abraça o sem sentido da vida e cerra, em seus braços, a única realidade tangível que consegue aceitar como verdadeira: sensações físicas e pequenos prazeres se opõem à ausência de ilusões e de expectativas diante do mundo.

Em uma carta para Carlos Drummond de Andrade, de 29 de março de 1927, Mário de Andrade, sem saber como consolar o amigo pela morte, após apenas minutos de vida, do seu filho Carlos Flavio, fala sobre sua própria relação com a perda.

Possuo sim e isso já tem horrorizado muito amigo meu quando eu falo pra ele que nem a morte de minha mãe que eu quero tanto bem me deixaria desinfeliz. Sofrer decerto que hei de sofrer se ela me vier a faltar porém ficar desinfeliz por causa disso juro pra você que não ficarei. Já tenho dado muitas razões dessa minha maneira bonita de ser porém não sei se nenhuma delas vale alguma coisa porque cada vez acho outras. Agora por exemplo me arrebentou na cabeça feito uma luz que isso me vem duma aceitação íntima permanente da realidade. E pois que essa realidade é deveras a coisa mais importante com que a gente tem de contar pra viver, vamos trabalhá-la, nos aproveitando de tudo o que ela dá, ela mesma, pra que a gente a vença quando ela é ruim. Aceitar a 
realidade primeiro, depois consertá-la. Num caso de morte como que a gente poderá consertar a realidade? [...]

Não é possível se comparar uma dor com outra dor... Ao menos para mim que sempre repeli a ideia de consolo. Não te irá parecer esta carta que sou seco por demais?... Estou imaginando isso. Homem que repele as memórias, que não quer saber de saudades, que despreza as consolações... Deve ser um homem seco. (ANDRADE, 2002, pp. 284-287)

Surpreende essa confissão, típica do gênero epistolar, que cito aqui para melhor entender a suposta indiferença e frieza de Meursault. Na verdade, como Mário de Andrade, o protagonista é justamente o homem que repele as memórias, que não quer saber de saudades, que despreza consolações e possui uma "aceitação íntima permanente da realidade". É a maneira - sem concessão - de aceitar primeiro a mais dura realidade: a morte. Se não há como consertá-la, o que mais fazer? Por que motivo ficar desinfeliz, se a única certeza de uma vida é a morte?

Para Meursault como para Silvestre, protagonista do conto "Os alicerces da realidade”, de José Régio (1973), há uma trajetória semelhante. É outro personagem que possui apenas um sobrenome, do latim silvester, que significa "bárbaro" (entendo o termo como o outro, o estrangeiro). Silvestre é um aposentado que passa repentinamente a duvidar da realidade e a enxergar a vida como uma pintura ou uma ficção.

Não obstante, de repente, por um momento, eis que tudo aquilo perdera a consistência da realidade: Era como se fosse um desenho, uma pintura, uma gravura, e ele próprio o herói duma ficção qualquer, vivendo uma história inventada não sabia por quem. (RÉGIO, 1973, p. 194)

Silvestre passa a inverter os alicerces da realidade que agora transformam-se em sonho: "Porém uma noite, acordando a meio da noite, acordou com esta frase na cabeça: 'A vida é um sonho'” (RÉGIO, 1973, p. 196). O protagonista do conto de José Régio começa a questionar as incongruências da realidade, comparando-as às de um sonho, e questiona a própria realidade e coerência da vida.

Às vezes sonhamos coisas disparatadas, sim. Quando as achamos disparatadas? Não é quando acordamos? E também, no que chamamos vida, não vemos nós mesmos que há disparates, absurdos, incongruências? Quantos mais não haverá pelos quais nem damos, simplesmente porque estamos sonhando! sonhando o sonho da vida. Quando acordarmos os veremos, quando acordarmos na morte do sonho da vida. Então veremos a irrealidade de tudo isto! (RÉGIO, 1973, pp. 205-206) 


\section{Mais adiante}

Pois que haverá de mais cómico, mais próprio a despertar a hilaridade, que o espetáculo de toda esta aérea humanidade feita de nada, a julgar-se de grande peso? Vista a coisa de alto, no seu conjunto e dum ponto de vista filosófico, talvez pudesse o vasto espetáculo inclinar-nos antes à melancolia; à seriedade, pelo menos. Mas há os pormenores. Há o ver em pormenor. Há as minúcias e os episódios. Ora nunca o nosso amigo Silvestre fora tão capaz de captar o episódio, e ver o pormenor! Chegava a tornar-se alucinante, ver, por exemplo, um só olho num rosto; ou a ponta dum nariz que mexe; ou uma discussão entre dois indivíduos, separando-os de tudo mais em volta [...]. Em saber que tudo, na vida, é inconsistente, falso, irreal, como nos sonhos sonhados dentro do próprio sonho da vida. (RÉGIO, 1973, pp. 206-207)

Diante do espetáculo da vida, Meursault recusa suas regras inconsistentes, falsas e irreais, recusa jogar o jogo. Como afirma Camus (1985, p. 14) em O mito de Sísifo,

Portanto, qual é esse incalculável sentimento que priva o espírito do sono necessário à sua vida? Um mundo que se pode explicar, até mesmo com más razões, é um mundo familiar. Mas, ao contrário, num universo repentinamente privado de ilusões e luzes, o homem se sente estrangeiro. Para este exílio, não há recurso, já que é privado de lembranças de uma pátria perdida ou da esperança de uma terra prometida. Esse divórcio entre o homem e sua vida, o ator e seu cenário, é propriamente o sentimento do absurdo. ${ }^{3}$

Numa carta para Drummond, de 19 de maio de 1929, Mário de Andrade descreve a contradição do amigo de uma maneira que talvez alumie o comportamento de Meursault.

Já sei mesmo como vocêé folha ao atá, levada pelos ventos. O engraçado é que se trata duma folha pensante, reagente como sensibilidade, que espiritualmente caminha contra os ventos mas que até já está achando um certo sabor nessa malinconia de se deixar levar. Porque apesar de todas as reações e projetos e desejos, você continua folha. Você jamais esquecerá que no meio do caminho tinha uma pedra. (DRUMMOND, 2002, p. 350)

A resposta de Drummond (2002, p. 351) numa missiva não datada, mas certamente do mesmo ano, é igualmente reveladora:

3"Quel est donc cet incalculable sentiment qui prive l'esprit du sommeil nécessaireà sa vie? Un monde qu'on peut expliquer même avec de mauvaises raisons est un monde familier. Mais au contraire, dans un univers soudain privé d'illusions et de lumières, l'homme se sent un étranger. Cet exil est sans recours puisqu'il est privé des souvenirs d'une patrie perdue ou de l'espoir d'une terre promise. Ce divorce entre l'homme et sa vie, l'acteur et son décor, c'est proprement le sentiment de l'absurdité." 
[Você] diz que jogou e perdeu, ao passo que eu não perdi porque não joguei, e me inveja. [...] Como se eu também não tivesse jogado... Como se até não fosse mais triste fazer o jogo cético que eu fiz, em que nunca tive esperanças e certezas para me abastecer, e sabia previamente que perderia. Eu também quero a honra de declarar que perdi o jogo.

Meursault é o sujeito que, à son insu, satiriza as relações falsas e as inconsistências da sociedade. Denuncia, elipticamente, o espetáculo de toda esta aérea humanidade feita de nada, a julgar-se de grande peso, como afirma o narrador do conto de José Régio. É sátira, não propriamente burlesca, pois composta de traços sutis e faltas. Se não recusa jogar o jogo, o personagem é ao menos bastante cético e deslocado.

\section{DO TELEGRAMA, OU A LUZ ESTRANGEIRA}

As primeiras linhas da obra são impressionantes pelo abalo que provocam em sua expressão de um sentimento de incompreensão, por parte de Meursault, com o súbito anúncio da morte de sua mãe. $O$ estrangeiro é inclusive citado entre as obras cujo início é marcante, como A metamorfose, de Kafka, por exemplo. O primeiro parágrafo é famoso e circula na internet. Não por acaso, há, nesse curto trecho da novela, uma elipse gramatical que constitui a chave de minha leitura e que participa desse princípio impactante. Trata-se do telegrama que o protagonista recebe.

O telegrama resulta de uma técnica de informação que visa à comunicação de um texto curto, emitido de forma rápida pelo telégrafo, através de sinais codificados. Pode ser considerado uma elipse, já que omite elementos da frase, nesse caso, o artigo ou possessivo e a conjugação do verbo. Mesmo com essas lacunas e a forma não flexionada da linguagem, para funcionar como elipse, ao leitor deveria ser possível sua compreensão, objetivo primeiro. Uma das mais famosas elipses, citada aliás por Compagnon no seu ensaio sobre o clássico, é um verso de Racine na tragédia Andrômaca, encenada pela primeira vez em 1667 no castelo do Louvre. No ato V, cena 5, encontramos o seguinte verso, num diálogo entre Hermione e Pirro: “Je t’aimais inconstant; qu'aurais-je fait fidèle?". A elipse se configura na ausência do trecho entre colchetes: "Je t'aimais inconstant; qu'aurais-je fait [si tu avais été] fidèle”. Em português, em tradução semântica: "Eu te amava inconstante; o que eu teria feito [se você tivesse sido] fiel?". Assim, essa omissão de um elemento do enunciado constitui uma figura de linguagem que funciona como um atalho para o sentido, 
que pode ou não produzir um efeito estético, em outras palavras, marcar o leitor pela sua forma peculiar. Do grego élleipsis, a palavra significa justamente "falta ou defeito". Cabe ao leitor restabelecer mentalmente seu significado. No caso de Meursault, ironicamente, ele se vê incumbido, ao precisar reconstruir mentalmente o enunciado, de dar sentido à morte da mãe. $\mathrm{O}$ repentino anúncio se dá provavelmente em um pedaço de papel, sem data, coberto por poucas palavras separadas por pontos, no qual a forma elíptica da expressão dá uma roupagem incoerente e fria a uma notícia tão séria, ao menos do ponto de vista daquela sociedade na qual o protagonista deambula. A mensagem não deve ter data porque o protagonista explicita claramente que não consegue situá-la no tempo, o que revela um problema de enunciação (categoria de tempo). Quando é aquele amanhã se não dissermos a partir de que data? Meursault fica aturdido não somente com a notícia, como também com a incoerência de sua forma. Camus utiliza duas vezes o advérbio "talvez" nesse curtíssimo parágrafo. Daí igualmente o seu "Cela ne veut rien dire" que não significa em francês, como veremos nas traduções para o português, "isso não quer dizer nada”, tradução literal que leva inclusive para outro sentido, ou "isso não esclarece nada”: não há nada a esclarecer, pois não há questionamento anterior.

Não é um acaso se Camus emprega esse tipo de comunicação. Há, nesse exato ponto, uma contradição entre a maneira fria que o diretor que compreendo aqui como representante dessa sociedade - anuncia a morte da mãe do protagonista, uma de suas pensionistas, e o discurso do promotor que insiste em condenar o postura fria e indiferentede Meursault, marcando esse crime com o selo de sua suposta falta de humanidade, sua constituição naturalmente monstruosa, o que faz com que seja condenado a perder a cabeça (guilhotina), como Silvestre (declarado louco). É aliás um debate bastante atual. O verdadeiro crime de Meursault, o assassinato do árabe, torna-se secundário. Essa inversão reforça ainda mais o sentimento do absurdo, que se estabelece na contradição, falta de sentido ou até mesmo hipocrisia que permeia em permanência os gestos e falas dos personagens. Basta observar, por exemplo, de que maneira o diretor do asilo se refere à mãe de Meursault, chamando-a de "senhora Meursault", "falecida" e, finalmente, "desaparecida" [la disparue], ao passo que o filho chama o tempo todo sua mãe de "maman/mamãe". Ou então a reação de Marie quando Meursault responde que casaria com outra mulher, se gostasse dela da mesma maneira. 
Após um tempo de silêncio, murmurou que eu era estranho, que sem dúvida me amava por causa disso, mas que talvez, um dia, eu lhe provocaria desgosto pelo mesmo motivo. Como permanecia calado, não tendo nada a acrescentar, tomou-me pelo braço sorrindo e declarou que queria casar comigo. (CAMUS, 1990, p. 70 $)^{4}$

Ou ainda o zelador do asilo que opina, de maneira sórdida, em pleno velório, sobre o fato de um falecido poder ser velado muito mais tempo em Paris do que em Marengo (Argélia), por causa do efeito do calor sobre o defunto. Até mesmo o funcionamento da língua, também regida pelas convenções sociais, soa como estranho na novela, porque é denunciado. O diretor chama Meursault de "filho" ou ainda "minha cara criança", que aparece entre aspas no texto, tratamento este que também é utilizado pelo padre. Por mais estranho que possa parecer, ele não é filho de nenhum dos dois. A língua aqui cria uma ilusão de intimidade que não existe e que parece ser questionada pelo emprego das aspas.

Convido-os a relerem a novela sob outra ótica. Afastem o olhar da perspectiva de Meursault. Atentem para as falas e ações dos personagens secundários. É como se Camus tivesse sutilmente introduzido o absurdo em cada situação de sua narrativa, em cada ação ou palavras de seus personagens.

Mas, para que o maquinário elaborado por Camus funcione, para uma apreensão mínima do sentimento do absurdo, dois elementos são fundamentais: primeiro, o leitor precisa se despir minimamente de seu estado de homem-lugar-comum, ou ao menos estar receptivo a tal mudança, o que também diz respeito ao tradutor. A novela deve (ou deveria) provocar uma reflexão. Segundo, no caso da tradução, é preciso que ela reproduza as lacunas do texto, pois tal interpretação é sobretudo possível graças ao seu caráter elíptico, simbolizado pelo telegrama. Passemos então às traduções.

A tradução de Antônio Quadros foi a primeira em língua portuguesa (de Portugal) a chegar ao Brasil, publicada pela Abril Cultural, em 1979, num volume que também incluía Estado de sítio, autoria de Maria Jacintha. Incrivelmente, malgrado Albert Camus ser prêmio Nobel de Literatura e $O$ estrangeiro constituir uma de suas mais importantes e conhecidas

4 "Après un autre moment de silence, elle a murmuré que j'étais bizarre, qu'elle m’aimait sans doute à cause de cela mais que peut-être un jour je la dégoûterais pour les mêmes raisons. Comme je me taisais, n'ayant rien à ajouter, elle m'a pris le bras en souriant et elle a déclaré qu'elle voulait se marier avec moi." 
narrativas, a primeira tradução em português brasileiro, de Valerie Rumjanek, foi publicada apenas em 1980, pelo Círculo do Livro. Ela iria se tornar a tradutora camusiana no Brasil, vertendo grande parte dessa obra, publicada pela Record. Atualmente, essa tradução da Rumjanek ainda é a única disponível no mercado, além da de Quadros, e conta com 42 edições (2017). A mesma tradução também é acessível pela editora Best Seller (grupo Record), nas edições BestBolso. Trata-se de um formato de bolso que está em sua $8^{a}$ edição (2016). Isso significa que a recepção da novela de Camus no Brasil se dá principalmente pela versão de Rumjanek, a menos que o leitor leia o texto em francês. Ora, nas traduções de que dispomos, ocorre algo surpreendente.

Antônio Quadros e Valerie Rumjanek, especificamente nesse trecho simbólico, restauraram a ordem, neutralizaram o estranhamento, familiarizaram o texto. Ambos não reproduziram a linguagem telegráfica, com todo seu mecanicismo sintético (conhecido por todos nós) e também perderam de vista o teor estético do qual esse telegrama se reveste.

Hoje, mamãe morreu. Ou talvez fosse ontem, não sei bem. Recebi um telegrama do asilo: "Sua mãe falecida. Enterro amanhã. Sentidos pêsames”. Isto não quer dizer nada. Talvez tenha sido ontem. (CAMUS, 1982, p. 155, tradução de Quadros) $)^{5}$

Hoje, mamãe morreu. Ou talvez ontem, não sei bem. Recebi um telegrama do asilo: "Sua mãe faleceu. Enterro amanhã. Sentidos pêsames." Isso não esclarece nada. Talvez tenha sido ontem. (CAMUS, 2017, p. 13, tradução de Rumjanek)

O caráter elíptico do telegrama foi minimizado. A falta foi preenchida. Em primeiro lugar, houve nos dois casos a inclusão do possessivo "sua". A versão de Quadros fica no meio do caminho com "Sua mãe falecida", mantendo a forma do particípio do verbo falecer com o possessivo. A versão da tradutora Valerie Rumjanek vai além, transformando o modo particípio em verbo conjugado no pretérito perfeito, passando, além disso, do "Cela ne veut rien dire", para "Isso não esclarece nada". A tradutora apagou a própria característica do telegrama, transformando-o em uma sentença convencional.

Essas traduções, com uma nova ordenação dos signos, provocaram um retorno ao texto de partida. Algo destoava. Algo importante. Vejamos o mesmo trecho em francês:

5 Todos os grifos das citações são de minha autoria. 
Aujourd'hui, maman est morte. Ou peut-être hier, je ne sais pas. J'ai reçu un télégramme de l'asile: "Mère décédée. Enterrement demain. Sentiments distingués." Cela ne veut rien dire. C'était peut-être hier. (CAMUS, 1990, p. 9)

O resultado é que o desconforto provocado pela forma fria de anunciar a morte da mãe é amenizado, desfazendo a atitude contraditória, para não dizer hipócrita, da sociedade que condena Meursault por sua indiferença.

No meu entendimento, a tradução poderia ser a seguinte:

\begin{abstract}
Hoje mamãe morreu. Ou talvez ontem, não sei. Recebi um telegrama do asilo:
"Mãe falecida. Enterro amanhã. Condolências." Isso não faz sentido. Pode ter sido ontem, talvez.
\end{abstract}

No telegrama está escrito "Mère décédée", ou seja, "Mãe falecida", nada mais. Não há pronome possessivo porque não é necessário. É um telegrama e esse tipo de comunicação funciona com esse princípio. A minha escolha pela palavra "condolências" reforça a ideia da fórmula meramente protocolar. Quanto ao "Cela ne veut rien dire", opto por "Isso não faz sentido". De fato, para o protagonista, nada disso faz sentido, a não ser a aceitação da única realidade tangível: a morte. O enunciado, além de mal formulado, já que aparentemente não apresenta data para situar aquele "amanhã", está envolvido em um manto de extrema frieza. A secura do anúncio, como disse, se dá justamente na ausência de possessivo e de forma verbal flexionada. Na versão que proponho, o caráter elíptico do texto permanece, mantendo seu impacto no leitor e a contradição do ato da sociedade ao condenar Meursault. Esse início deve fazer eco com o julgamento para que o sentimento do absurdo se destaque.

De um ponto de vista teórico, quais são as reflexões que surgem dessa leitura do texto? Quais as consequências para o gesto tradutório? E para a tradução da literatura em prosa?

O telegrama, enquanto forma de comunicação comum, prática e rápida, pode ser compreendido como uma "informação semântica", conceito de Max Bense retomado por Haroldo de Campos (2006, pp. 3134) no famoso ensaio "A tradução como criação e como crítica". Diria até mesmo que esse telegrama transita entre a informação documentária e a semântica, já que é também uma sentença-registro, que reproduz algo observável: a senhora Meursault faleceu e o enterro será amanhã. É a expressão dos sentimentos que leva o texto ao semântico, "sentidos pêsames" (na tradução de Valerie Rumjanek - 2017, p. 13), que é, ainda mais na cultura francesa, uma fórmula considerada polida de expressar 
consideração, mas que se revela vazia e é empregada apenas por convenção social. São fórmulas obrigatórias ao final de cartas e e-mails. Em francês fica ainda mais óbvio, pois "sentiments distingués" nada mais é, literalmente, do que "sentimentos distintos", ou seja, sentimentos de consideração, de distinção. Em outras palavras, o telegrama procura comunicar algo de maneira sintética, privilegiando ao máximo o sentido. A ordenação de signos admitiria outra organização no telegrama, o que a distinguiria da informação estética, como se observou anteriormente: Sua mãe falecida/ Sua mãe faleceu/ Mãe falecida.

No entanto, parece-me que o telegrama também é uma “informação estética”. Sua alteração produz uma grande mudança na leitura, como vimos das traduções de Quadros e Rumjanek. De fato, para que esse sentimento do absurdo tome corpo, a ordenação dos signos deve se aproximar ao máximo do texto de partida, tornando-se, assim, uma sentença absoluta, como teorizou Albercht Fabri, citado por Campos (2006a, p. 31) naquele famoso ensaio.

Assim sendo, o telegrama permite questionar esses conceitos, que já não são mais estanques - ou informação documentária ou semântica ou estética. Sua função, na novela, também está vinculada a uma realização singular. Em outras palavras, a mensagem poderia a rigor ser reformulada, sem alteração do sentido. É o objetivo primeiro do telegrama de modo geral. Mas Camus parece ter empregado essa ordenação de signos justamente pela sua forma elíptica e sintética. Transmitir um sentido não é mais o único objetivo, senão associado a um agenciamento específico de palavras e lacunas. O mero telegrama torna-se agora sentença absoluta nas mãos do autor. Os conceitos de Bense se sobrepõem.

Ao buscar as acepções da palavra "étranger" nos dicionários Littré e Trésor (CNRLT), deparei-me com o termo pictural "lumière étrangère", oriundo de um dicionário de pintura, escultura e gravura do século XVIII. Este também contém um tratado. Trata-se do Dictionnaire portatif de peinture, sculpture et gravure; avec un traité pratique des différentes manières de peindre, dont la théorie est développée dans les articles qui en sont susceptibles, ${ }^{6}$ autoria de um beneditino, Antoine-Joseph Pernety (1716-1796), publicado em 1757. Ao final do verbete "Étranger", encontra-se a definição seguinte:

6 "Dicionário portátil de pintura, escultura e gravura; com um tratado prático das diferentes maneiras de pintar, cuja teoria é desenvolvida nos artigos que delas são suscetíveis.” 
On appelle aussi lumière étrangère une lumière différente de la principale, \& ménagée artistement pour le bon effet du tableau. (PERNETY, 1757, p. 308)

Chama-se também de luz estrangeira uma luz diferente da principal \& disposta artisticamente para o bom efeito do quadro.

Logo lembrei dos quadros seiscentistas (barroco), com seus fortes contrastes de luz e sombra. Mas o que talvez represente esse termo de pintura é o "Fishermen at sea" (1796 - Royal Academy), do pintor inglês Joseph Mallord William Turner (1775-1851), especializado em paisagens. O quadro representa a luta de três barcos de pescadores, em meio às ondas do mar na escuridão. Os efeitos de luz têm origem sobretudo em dois pontos. A lanterna da pequena embarcação, quase ao centro da paisagem, trêmula e sutil, que contrasta com a potência da luz da lua. Tratar-se-ia nessa tela do poder da natureza sobre o destino da humanidade, sobre aqueles pescadores em particular. Essa obra pictórica de Turner ilustra o conceito de luz estrangeira. Resta saber se, no caso da literatura em prosa, tal luz surge com a potência da lua ou a sutileza da lanterna.

Na novela de Camus, a luz estrangeira é o telegrama que destoa ou brilha com mais força no conjunto dos efeitos do texto. É essa luz que fornece, como um faixo deslocado, uma pista para a leitura da obra, já que aponta de maneira impactante, e já no famoso início da narrativa, para um panorama maior de falas e ações absurdas da sociedade, que são apresentadas de forma mais discreta. A frieza do telegrama denuncia a hipocrisia dessa sociedade que condena Meursault pela sua suposta indiferença.

\section{CONSIDERAÇÕES FINAIS}

Em suma, o modus operandi dessa luz estrangeira é o contraste. A sua técnica é o domínio do contraste, para obter o efeito geral do quadro, assim como a sombra, ao passo que as figuras ganham volume, detalhe, e permitem exprimir conceitos e ideias. O termo pode ser compreendido não exclusivamente no sentido literário, a arte de contrastar, graças a um meio de expressão, por oposição de ritmos, palavras e ideias. O termo é empregado no século XVI, por Montaigne (1967), em "A propósito de um costume da ilha de Céos", no segundo livro dos Ensaios, nas acepções de "oposição, debate, luta, combate". O ensaio em questão começa coincidentemente com o problema do suicídio, o que nos leva ao tema central de $O$ mito de Sísifo. O papel do contraste é o de destacar o outro 
elemento e de afirmar a oposição, o debate, ou até mesmo a luta dessas visões opostas de mundo. Nesse sentido, o telegrama salienta, como a luz da lua no quadro de Turner, o combate de Meursault contra a falsa natureza das convenções e ilusões da vida. É a luta entre o homem absurdo e o homem-lugar-comum. É um embate discreto, que deriva, assim como as canoas dos pescadores, em meio à escuridão, ou como a escuma das vagas até que, finalmente, "o mar arrastou um sopro espesso e ardente" [la mer a charrié un souffle épais et ardente] (CAMUS, 1990, p. 95), sobre o protagonista.

Assim, esse contraste do telegrama, aqui ilustrado e teorizado com o termo pictural de luz estrangeira, parece-me central para a interpretação da obra e a compreensão da filosofia de Camus, que clama, na prática pensante da tradução, por um gesto singular do tradutor. Não é tanto uma teoria aplicada a um gesto tradutório, pois, ao meu ver, o telegrama fragiliza os conceitos de Bense. Com efeito, o anúncio da morte da mãe de Meursault pode ser considerado, simultaneamente, uma informação semântica e uma informação estética. Pertence ao campo semântico porque, apesar de minimalistas, suas palavras desconexas formam uma mensagem, transmitem um recado urgente que se poderia parafrasear. E a essa formulação simplificada de um sentido, agrega-se, no caso específico da novela, uma função estética, já que sua forma elíptica reveste a mensagem de incoerência e frieza: "Mãe falecida. Enterro amanhã. Condolências”. Mas de que modo situá-la, se não há mais classificação possível? Daí o emprego do conceito de luz estrangeira, pois ainda que seja elemento muito semelhante à luz empregada no quadro, destoa de alguma forma da luz geral, é-lhe estrangeira, não como sendo de outra "natureza" - elemento distinto - mas apenas deslocado do seu contexto, desconexo na sua relação com o Outro: a maior parte da luz da tela. É a leitura crítica do texto que força a mão e exige uma prática pensante. Como anunciei na introdução, diante de um texto como $O$ estrangeiro, a posição tradutória deve ser a de resistir à pulsão de aplacar o estranhamento para possibilitar sua acolhida: o estrangeiro do/no Estrangeiro. O primeiro gesto do tradutor deveria ser de resistência.

O problema apresentado na tradução desse excerto estimula uma reflexão no campo da teoria da tradução. Traduzir literatura em prosa não é, como se sabe, apenas traduzir o sentido. E o exemplo de $O$ estrangeiro devechamara atenção para as dificuldades específicas da tradução de textos em prosa. Tal reflexão problematiza (ou flexibiliza) conceitos sobretudo 
empregados na tradução de poesia, como vimos no ensaio de Haroldo de Campos. Verter um texto em prosa cuja linguagem, em aparência, não é marcada por uma função poética - como seria uma obra como Grande sertão: veredas -, passa a ganhar outra dimensão, flexibilizando reflexões teóricas reservadas à (ou mais comumente presentes na) tradução do poema. Como disse Antoine Berman (2013, p. 67): "Na medida em que a prosa é considerada inferior à poesia, as deformações da tradução são aqui melhor aceitas - quando não passam despercebidas". Não acredito que se possa afirmar que a prosa é inferior à poesia, não sem provocar duros debates. A pertinência da reflexão de Berman está na afirmação de que as deformações passam despercebidas na prosa literária. No caso de $O$ estrangeiro, as consequências são grandes, já que, a meu ver, a leitura da obra pode derivar para algo contrário ao pensamento de Camus ou para interpretações simplórias: "Meursault é louco ou excêntrico". Cabe ainda ressaltar que, aparentemente, nas traduções analisadas, não há projeto de tradução que intente propor uma leitura específica, transcriação ou reencenação. Não temos acesso a paratextos dos tradutores. Assim, o gesto do tradutor, como tentei demostrar, pode ter sido guiado, de maneira inconsciente, por uma pulsão ditada pelo restabelecimento de uma suposta ordem. Se não há como evitar escolhas inconscientes, a experiência da tradução da novela camusiana alerta para o risco desse gesto ordenador. No mais, o aparato teórico da tradução do poema pode ser um auxílio de grande valia para o tradutor de romances, contos, e outros textos em prosa. A essa posição tradutória, cabe aliar uma leitura crítica da obra, da palavra preto no branco (o telegrama), entranhada de lacunas.

Finalizando, O estrangeiro não é, como afirma Manuel da Costa Pinto (2017, p. 5), no prefácio da tradução de Valerie Rumjanek, um romance que "inaugura uma espécie singular de escrita transparente, neutra". Também não estamos diante de uma consciência esvaziada, estranha (ou "estrangeira") a tudo (CAMUS, 2017, p. 5). A falta de manifestação explícita dessa consciência, por parte do personagem narrador, antes significa que não se traduz em palavras, mas através de um sentimento do absurdo que toma forma apenas pelo gesto do protagonista, gauche e cético. $\mathrm{O}$ divórcio do homem, da concepção de homem de Camus, manifesta-se, numa sorte de peça de teatro, como que pelo corpo de um ator, pouco a pouco consciente de estar atuando em uma fábula, e não na vida real. É a consciência ainda borrada de Meursault, latente, talvez como uma 
intuição - no sentido bergsoniano (Essai sur les données immédiates de la conscience, 1889) -, um pensamento ainda no limiar da consciência, que Camus chama de "sentimento".

É bom lembrar que em francês, "avoir le sentiment" significa "ter a sensação de" e que "exposer son sentiment" tem sentido de "maneira de pensar, de julgar, ter um ponto de vista”. Esse esvaziamento não é o da consciência do personagem, mas sim o da exteriorização de sua consciência. $\mathrm{O}$ fato de um personagem não explicitar seus sentimentos ou pensamentos não equivale a dizer que não sente ou pensa. Ter o sentimento do absurdo, é o aflorar de uma consciência ainda confusa e não formulada por um narrador que pouco diz ou sabe. Assim, a narrativa de Camus não é neutra ou transparente. É resultado do voluntário cinzelar de uma elipse trançada por fios de arame farpado. Se um clássico, como disse Compagnon, é entranhado de diferenças, a novela de Camus é entranhada de faltas (ou lacunas) - do narrador/protagonista insciente ao telegrama - que o tradutor precisa preservar, se o projeto de tradução for recriar sua literariedade. E é no contraste, assim como a sombra surge da luz, entre as ações do protagonista e a ausência de explicações, que nasce a força do texto, e o desconforto produzido no leitor. O divórcio de Meursault com a sociedade é o divórcio do ator com o papel que ele está interpretando. O homem absurdo não é mero estranho, sujeito indiferente, frio ou seco, como se questiona Mário de Andrade. Não pode ser sentenciado como louco, caso de Silvestre, ou como monstro, nas palavras do promotor. O único mal que o aflige éa "loucura da sinceridade" [la folie de la sincérité], como afirmou Camus (1997) em uma entrevista, que faz parte do documentário Un combat contre l'absurde [Um combate contra a absurdo]. É o sujeito que jamais quer dizer mais do que sente, atitude perfeitamente absurda naquela sociedade, e ainda mais na nossa: Sociedade da transparência (HAN, 2017). Meursault é um homem que possui o sentimento do absurdo, que despertou de seu estado de homem-lugar-comum e perturba a ordem do dia. A única reação possível éa revolta (que se manifestará ao final da novela). Sentindo-se preso ao movimento elíptico da vida, como Sísifo empurrando a rocha, compreendeu que nada disso faz sentido. Cabe ao tradutor recriar esse sutil maquinário. 
Remate de Males, Campinas-SP, v.38 n.2, pp. 683-702, jul./dez. 2018 - 701

\title{
TRANSLATING THE FOREIGNER, BY ALBERT CAMUS: THINKING THE FOREIGN LIGHT IN PROSE LITERATURE
}

\begin{abstract}
The objective of this article is to present a reading of the novel The foreigner, by Albert Camus, first published in 1942, based on the concept of "lumière étrangère" [foreign light], coming from the visual arts. The analysis of the protagonist is crucial and is based on works by José Régio, D. H. Lawrence or even letters by Mario de Andrade. In a second moment, it is intended to detail the singular gesture that emanates from the translation of this work that intends to assimilate consciously that foreign element. Next, it will be necessary to highlight the divergences of our translation into Brazilian Portuguese, with those available in the market, to show that the foreign element can cause great discomfort for the translator who will tend to neutralize it. In a third moment, it is tried to establish a reflection, starting from the translation exercise, to highlight specific problems to the translation of literary texts in prose. This reflection passes through theoreticians like Antoine Berman and Haroldo de Campos, notably in the problematization of the concepts of "semantic information" and "aesthetic information" elaborated by Max Bense.
\end{abstract}

Keywords: Camus; The Foreigner; Translation.

\section{REFERÊNCIAS}

ANDERS, Günther. Kafka: pró \& contra. Trad. Modesto Carone. 2. ed. São Paulo: Cosac Naify, 2007.

ANDRADE, Carlos Drummond de. Carlos e Mário: correspondência entre Carlos Drummond de Andrade - inédita - e Mário de Andrade: 1924-1945. Rio de Janeiro: Bem-Te-Vi Produções Literárias, 2002.

COTE-OSTIGUY, Catherine. André Gide et la quête du roman: la poursuite d'un idéal romanesque depuis Paludes jusqu'aux Faux-monnayeurs. Dissertação (Mestrado) Université McGill, Montréal, 2013.

BERGSON, Henri. Essai sur les données immédiates de la conscience. Paris: Félix Alcan, 1936.

BERMAN, Antoine. Pour une critique des traductions: John Donne. Paris: Gallimard, 1995.

BERMAN, Antoine. A tradução e a letra ou do albergue do longínquo. Trad. Marie-Hélène C. Torres, Mauri Furlan, Andreia Guerini. 2. ed. Tubarão/Florianópolis: Copiart/ PGET/UFSC, 2013.

CALVINO, Italo. Mundo escrito e mundo não escrito - artigos, conferências e entrevistas. Trad. Maurício Santana Dias. 1. ed. São Paulo: Companhia das Letras, 2015.

CAMPOS, Haroldo de. Da tradução como criação e como crítica. In: CAMPOS, Haroldo de. Metalinguagem e outras metas. São Paulo: Perspectiva, 2006a. 
CAMPOS, Haroldo de. Metalinguagem e outras metas: ensaios de teoria e crítica literária. São Paulo: Perspectiva, 20o6b.

CAMUS, Albert. Estado de sítio; O estrangeiro. Trad. Maria Jacintha e Antônio Quadros. São Paulo: Abril Cultural, 1982.

CAMUS, Albert. Le mythe de Sisyphe. Paris: Gallimard, 1985.

CAMUS, Albert. L'étranger. Paris: Gallimard, 1990.

CAMUS, Albert. O estrangeiro. Trad. Valerie Rumjanek. 8. ed. Rio de Janeiro: BestBolso, 2016.

CAMUS, Albert. O estrangeiro. Trad. Valerie Rumjanek. 42. ed. Rio de Janeiro: Record, 2017.

CNRTL - Centre National de Ressources Textuelles et Lexicales. Dicionário on-line. Disponível em: <http://www.cnrtl.fr/definition/>.

COMPAGNON, Antoine. Le classique. 2011. Disponível em: <https://www.college-defrance.fr/site/antoine-compagnon/articles_en_ligne.htm>. Acesso em: 10 abril 2018.

HAN, Byung-Chul. Sociedade da transparência. Trad. Enio Paulo Giachini. Petrópolis, RJ: Vozes, 2017.

LAWRENCE, David Herbert. Caos em poesia. Tradução Wladimir Garcia. Florianópolis: Cultura e Barbárie, 2016.

LITTRÉ, É. Dictionnaire de la langue française [on-line]. Disponível em: <https://www. littre.org/>.

MONTAIGNE. Oeuvres complètes. Paris: Seuil, 1967.

PERNETY, Antoine-Joseph. Dictionnaire portatif de peinture, sculpture et gravure; avec un traité pratique des différentes manières de peindre, dont la théorie est développée dans les articles qui en sont susceptibles. Paris: Chez Bauche, 1757. Disponível em: $<$ gallica.bnf.fr >. Bibliothèque Nationale de France.

COSTA PINTO, Manuel da. Prefácio. In: CAMUS, Albert. O estrangeiro. Trad. Valerie Rumjanek. 42. ed. Rio de Janeiro: Record, 2017, pp. 5-10.

RÉGIO, José. Há mais mundos. Porto: Brasília Editora, 1973.

UN COMBAT contre l'absurde. Direção: James Kent. France: Arte, 1997. Disponível em: <https://www.youtube.com/watch?v=k9_dgoXxIBI>. Acesso em: 15 mar. 2018.

TURNER, Joseph Mallord William. Fishermen at sea. 1796. Óleo sobre tela de $91.44 \times \mathbf{1 2 2 . 2 4}$ cm. Royal Academy, Londres. Disponível em: <https://www.tate.org.uk/art/ artworks/turner-fishermen-at-sea-to1585>. Acesso em: 4 nov. 2018. 